\title{
Nuclear DNA content of fine needle aspirates of invasive ductal carcinomas of the breast
}

\author{
Sudip Sarker ${ }^{1,2, *}$, Allan Spigelman ${ }^{2}$, Marjorie Walker $^{3}$ and Dulcie Coleman ${ }^{1}$ \\ ${ }^{1}$ Cytopathology, Cytogenetics, ${ }^{2}$ Academic Surgical and ${ }^{3}$ Histopathology Units, \\ St Mary's Hospital Medical School, Imperial College of Science, Technology and Medicine, \\ University of London, London W2 $1 N Y$, UK
}

Received 23 April 1996

Revised 25 October 1996

\begin{abstract}
Patients with aggressive breast cancers benefit from chemotherapy prior to surgery. If the biology of the breast cancers were better characterised pre-operatively, more patients at risk could be offered chemotherapy. We have assessed nuclear DNA content of fine needle aspirates (FNA) of 103 invasive ductal breast cancers and compared this to tumour size, node status and histological grade. Median follow-up was 18 months so no prognostic studies were made. Diploid and non-diploid tumours were distributed equally in node negative and positive patients. However non-diploidy status increased in line with known prognostic markers of tumour size and histological grade. This suggests that ploidy might contribute to the pre-operative assessment of prognosis. We conclude that nuclear DNA of breast cancer FNAs may be of value in the pre-operative biological assessment of breast cancer patients.
\end{abstract}

Keywords: Breast, carcinoma, cytology, DNA

\section{Introduction}

The treatment of breast cancers has changed in the last few years, from radical surgery to breast conserving surgery with or without adjuvant therapy $[25,34,38]$. Patients can now have pre-operative neo-adjuvant therapy and/or anti-oestrogen therapy prior to any surgery with the aim of shrinking the tumour and prolonging survival. Knowledge of biological status pre-operatively of the tumour would help in the selection of therapy as the response is dependent on the histological grade of the cancer. High grade tumours respond better to chemotherapy than low grade tumours which in turn respond better to anti-oestrogen therapy. Acceptance of prognostic grading of histological specimens of invasive ductal cancers has been used for many years [4], however, this can only be confirmed retrospectively, after the tumour has been excised. This does not permit the breast cancers to be prognostically graded prior to any surgery or neo-adjuvant therapy. There has been one study which

\footnotetext{
${ }^{*}$ Correspondence to: Dr S.K. Sarker, Cytopathology and Cytogenetics Unit, Clarence wing, St Mary’s Hospital Medical School, Praed Street, London W2 1NY, UK.
} 
compared histological grading to ploidy on FNA of breast cancers, but the study evaluated only a small sample of patients [10].

We have therefore elected to do ploidy studies on fine needle aspirates (FNA) to determine if this improves evaluation of ploidy status which may be an independent prognostic factor in breast cancers when tissue sections $[5,7-9,13,14,19,24,32,33,36]$ or cytological specimens are used $[1,3,30]$. In present study we have compared the ploidy status of FNAs to the TNM staging system and to histological grade.

\section{Materials and methods}

\subsection{Diagnostic cytological smears}

FNA samples were obtained from women attending the Breast Unit at St Mary's Hospital, London with invasive ductal breast cancers. They were obtained using a $20 \mathrm{G}$ needle and a $10 \mathrm{ml}$ syringe. Smears were prepared from the aspirates, air dried and stained with modified Giemsa. They were analysed under light microscopy and reported according to the Royal College of Pathologists' guidelines for malignant lesions [27]. Available for nuclear DNA studies were consecutive 103 invasive ductal breast carcinomas.

\subsection{Nuclear DNA cytological smears}

After reporting the pre-operative diagnostic smear slides were placed in xylene for $72 \mathrm{hrs}$ to remove the coverslip and synthetic mounting resin. The slides were then destained in $100 \%$ methanol for $15 \mathrm{~min}$ and washed in distilled water for $10 \mathrm{~min}$. The slides were then fixed in $10 \%$ neutral buffered formalin for $30 \mathrm{~min}$ and then in $5 \mathrm{~N} \mathrm{HCl}$ for $1 \mathrm{~h}$ which hydrolyses the ribose-purine bonds in the DNA to give sugar aldehyde residues [11]. The slides were then Feulgen stained using a CAS ${ }^{\mathrm{TM}}$ DNA ploidy staining kit following the manufacturers staining protocol which uses the thionine reaction (Beckton/Dickinson, Belgium). The Feulgen dye couples stoichiometrically via the Schiff reaction to the sugar aldehyde to give a blue colour [2]. The stained slides were then placed sequentially in acid alcohol, $100 \%$ ethanol and xylene. The slides were then mounted with coverslips using synthetic resin.

\subsection{DNA rat hepatocytes controls}

Rat hepatocytes embedded on a slide (Beckton/Dickinson) were Feulgen stained in the same manner of the previous specimens. The cells were used to calibrate the human DNA content and also acted as a control for the intensity of the Feulgen staining, and were placed in each batch of slides. Two rat hepatocyte control slides were placed in each batch of 12 specimens. The calibration slides were part of the multicentre European Quality Control Program run by Beckton/Dickinson. The coefficient of variation was $3.2 \%$ for the rat hepatocytes.

\subsection{DNA tonsillar controls}

Aspirate smears of normal tonsillar tissue were also used as controls and were Feulgen stained in the same manner as previously described. Two such controls were placed in each batch of specimens, they acted as a control for the staining procedure as well as a normal control the DNA index. Their coefficient of variation was $2.9 \%$. 


\subsection{Image analysis}

The Feulgen stained cytological slides were analysed on a CAS ${ }^{\mathrm{TM}} 200$ image analysis system (Beckton/Dickinson). This is a video-based interactive image cytometer that uses the sum of the optical density of each Feulgen stained nucleus to calculate the amount of DNA present $[21,28]$. The ploidy status of a cytological sample was based on the analysis of at least 100 cells (range 100-220). The DNA indices of the cytological specimens were recorded. DNA indices of cytological specimens of breast cancers $<1.20$ were classified as diploid with a coefficient of variation of $2.4 \%$ and $>1.20$ as non-diploid with a coefficient of variation of $8.1 \%$.

\subsection{Histological specimens}

Tissue sections of $2 \mu \mathrm{m}$ were taken from the post-operative surgical specimens and routinely processed for light microscopy from all those patients included in the study to confirm the histological diagnosis of breast cancer. They were fixed in $10 \%$ neutral-buffered formalin and embedded in paraffin and stained with Haemotoxylin and Eosin for histological studies. Histological specimens were reported in accordance with national guidelines [27]. Each patient had their TNM stage measured using clinical pathological findings.

\section{Results}

There were a total of 103 women with a mean age of 52 yrs (range 31-82). Of the patients $59 \%$ were node negative and $41 \%$ were node positive. Comparing tumour size, $29 \%$ were less than $2 \mathrm{~cm}, 46 \%$ between $2-5 \mathrm{~cm}$ and $25 \%$ greater than $5 \mathrm{~cm}$. Of the invasive ductal tumours $15 \%$ were grade $1,45 \%$ were grade 2 and $40 \%$ were grade 3 . The cancers non-diploid were $70 \%$, and $30 \%$ were diploid. The women were $25 \%$ premenopausal and $75 \%$ postmenopausal. The results are summarised in Tables 1 and 2. Comparison of ploidy status and tumour size and histological grade is graphically displayed in Figs 1 and 2. The median follow-up time was 18 months thus no prognostic studies were made because they would not be of any clinical value.

Table 1

Patient characteristics

\begin{tabular}{|c|c|c|}
\hline Character & Number of patients & Percentage of total \\
\hline Node positive & 42 & $41 \%$ \\
\hline Node negative & 61 & $59 \%$ \\
\hline Tumour size $<2 \mathrm{~cm}$ & 30 & $29 \%$ \\
\hline $2-5 \mathrm{~cm}$ & 47 & $46 \%$ \\
\hline$>5 \mathrm{~cm}$ & 26 & $25 \%$ \\
\hline Histological Grade I & 15 & $15 \%$ \\
\hline - & 46 & $45 \%$ \\
\hline III & 42 & $40 \%$ \\
\hline Premenopausal & 26 & $25 \%$ \\
\hline Postmenopausal & 77 & $75 \%$ \\
\hline Diploid & 31 & $30 \%$ \\
\hline Non-diploid & 72 & $70 \%$ \\
\hline
\end{tabular}


Table 2

Ploidy status, node involvement, tumour size and histological grade

\begin{tabular}{lrc}
\hline Variables & Diploid & Non-diploid \\
\hline Node negative & $18(30 \%)$ & $43(70 \%)$ \\
Node positive & $14(33 \%)$ & $28(67 \%)$ \\
Tumour size $<2 \mathrm{~cm}$ & $15(50 \%)$ & $15(50 \%)$ \\
$2-5 \mathrm{~cm}$ & $14(30 \%)$ & $33(70 \%)$ \\
$>5 \mathrm{~cm}$ & $3(12 \%)$ & $23(88 \%)$ \\
Histological Grade I & $9(60 \%)$ & $6(40 \%)$ \\
II & $15(33 \%)$ & $31(67 \%)$ \\
III & $14(34 \%)$ & $27(66 \%)$ \\
\hline
\end{tabular}

Values in parentheses are percentages of ploidy status in each variable.

\section{Percentage of group}

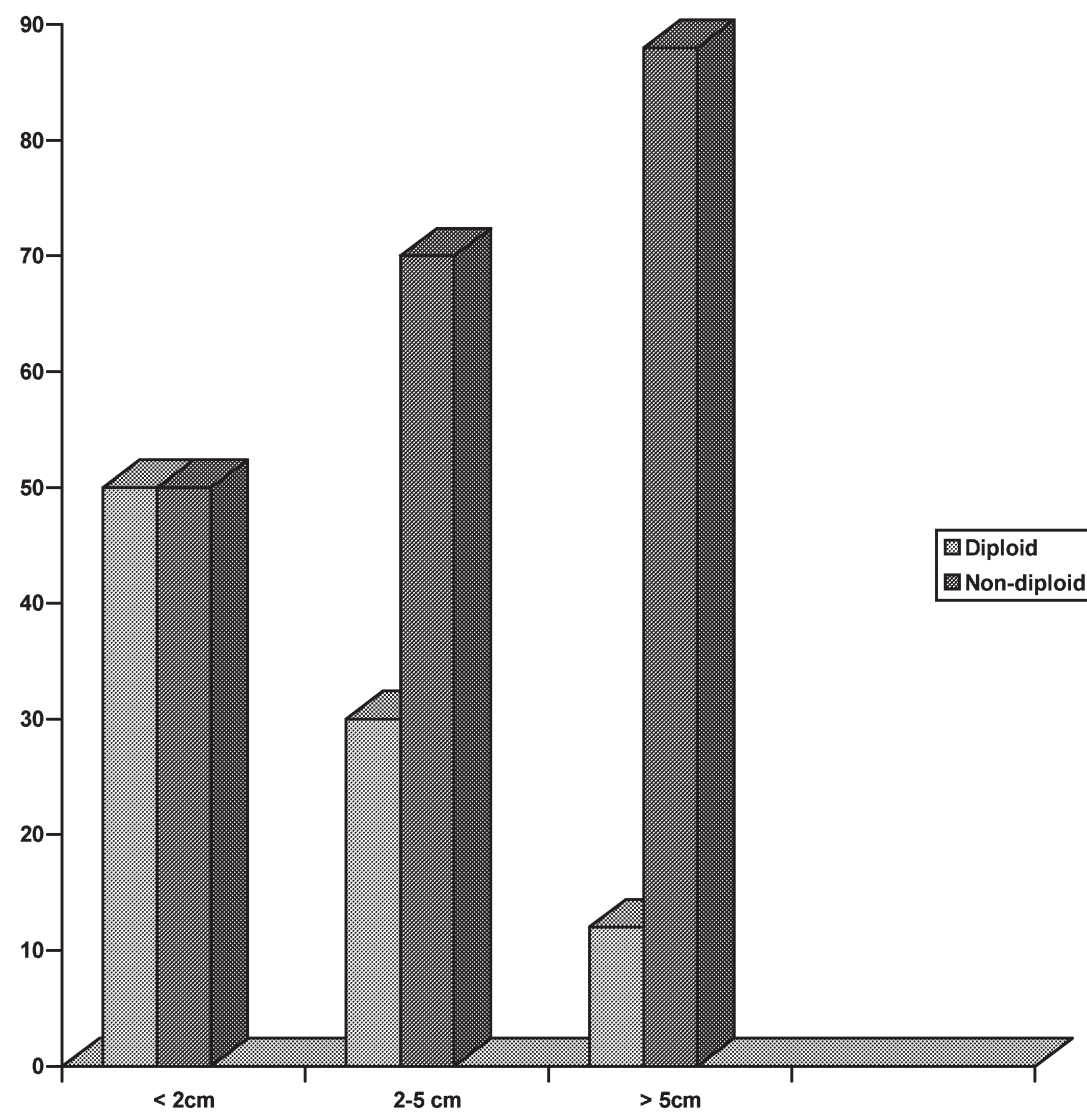

Tumour Size of Breast Cancers

Fig. 1. Distribution of diploid and non-diploid in fine needle aspirates of breast cancers compared to tumour size. 


\section{Percentage of group}

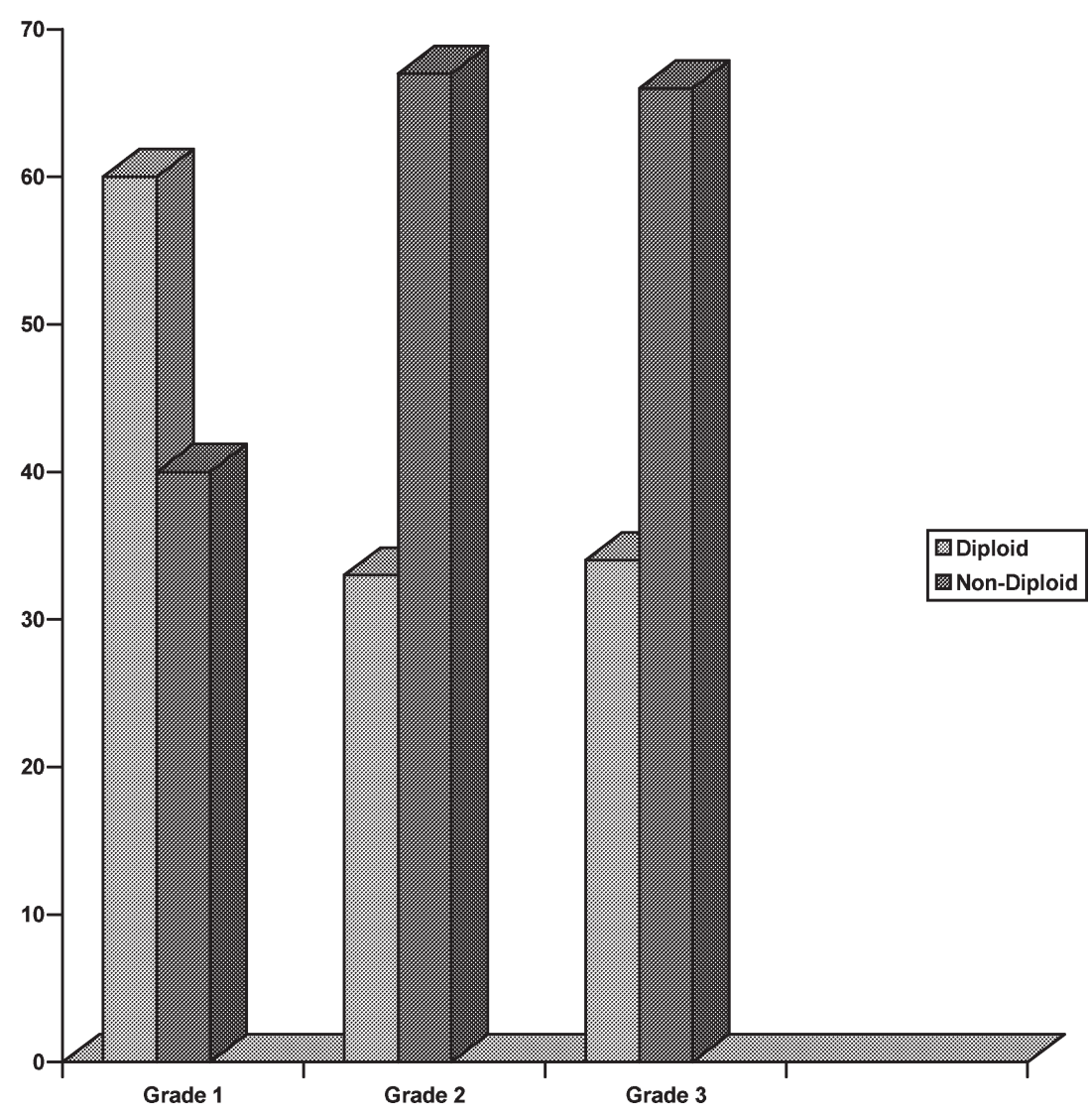

Breast Cancer Histological Grade

Fig. 2. Distribution of diploid and non-diploid of breast cancer cytology compared to histological grade.

\section{Discussion}

Nuclear DNA content is a reflection of the amount of DNA present in the chromosomes of the cell. It is usually defined as ploidy status. The issue of whether the DNA ploidy classification (diploid, tetraploid or aneuploid) is an independent prognostic factor is less clear, and not all studies are in agreement $[5,7-9,13,14,19,24,32,33,36]$. These studies were made on tissue sections of breast cancers, and flow cytometry was used to determine ploidy status. There have only been a few prognostic studies of nuclear DNA which have used cytological specimens of breast cancers $[1,3,30]$.

It has been shown that ploidy status of tissue sections and cytological specimens of breast cancers using flow cytometry are comparable [20]. Also comparable are the measurements of nuclear DNA in breast cancer cytology using flow and image cytometry [16]. The latter method being more advantageous as cells are sparse in cytological specimens and debris and benign cells are eliminated from the analysis [15]. Although nuclear DNA content of breast lesions are comparable with image 
cytometry on tissue sections and FNAs [29], cytological specimens are preferable since tissue sections are liable to contain sliced tumour nuclei [15]. We have shown that ploidy of FNAs of breast cancers correlate with histological grading and with tumour size and therefore may have a prognostic role in the pre-operative treatment of these patients.

More patients are being given pre-operative treatment in the form of neo-adjuvant therapy and anti-oestrogen therapy. It would be of clinical value if the tumour biology could be measured prior to any treatment. Studies prognostically grading breast cancer cytology have been carried out with differing results $[6,12,13,17,22,23,26,28,31,35,37]$. Our results show that determination of ploidy status of invasive ductal breast cancers can be easily achieved on FNAs using image cytometry. We have found there is an equal distribution of ploidy status in node positive and negative patients which is unlike some previous studies [12,18]. Our distribution of ploidy status, 30\% diploid and $70 \%$ non-diploid is similiar to previous reports $[9,12,18]$. When comparing the ploidy status to tumour size and to histological grade, it is evident that non-diploid cells are present in a higher frequency as tumour size and histological grade increases. The latter relationship has been previously observed $[18,24]$, but the relationship between tumour size and ploidy status differs in these studies. Because tumour size and histological grade has long been established as having prognostic value, DNA ploidy status of FNAs of invasive ductal cancers may also have a possible prognostic role.

We therefore aim to follow up this group of patients in order to evaluate the prognostic role of nuclear DNA content in FNAs of breast cancers. This may lead to a better choice of treatment regimes available to breast cancer patients and to a better assessment of these patients prior to any treatment.

\section{Acknowledgements}

The staff of the Departments of Cytopathology and Histopathology at St Mary's Hospital, London, W2 1NY, UK.

\section{References}

[1] M. Aubele, G. Auer, A. Voss, V. Falkmer, L.E. Rutquist and H. Hofler, Different risk groups in node negative breast cancer: prognostic value of cytophotometrically assessed DNA, morphometry and texture, International Journal of Cancer 63(1) (1995), 7-12.

[2] J.W. Bacus and L.J. Grace, Optical microscope system for standardised cell measurements and analysis, Appl. Optics 26 (1987), 3280-3293.

[3] I. Balsleu, I.J. Christensen, B.B. Rasmussen et al., Flow cytometric DNA ploidy defines patients with poor prognosis in node negative breast cancer, International Journal of Cancer 56(1) (1994), 16-23.

[4] H. Bloom and W. Richardson, Histological grading and prognosis in breast cancer, British Journal of Cancer 11 (1957), 359-377.

[5] R. Camplejohn, C.M. Ash, C.E. Gillett, B. Raikundalia, D. Barnes, W.M. Gregory, M. Richards and R. Millis, The prognostic significance of DNA flow cytometry in breast cancer: results from 881 patients treated in a single centre, British Journal of Cancer 71 (1995), 140-145.

[6] S. Ciatto, R. Bonardi, A. Herd-Smith, Cariaggi, M. Confortini and G. Bulgaresi, Prognostic value of breast cancer grading: a retrospective study of 213 cases, Diagnostic Cytopathology 9 (1993), 160-163.

[7] G. Clark, L. Dressler, M. Owens, G. Pounds, T. Oldaker and W. McGuire, Prediction of relapse or survival in patients with node-negative breast cancer by DNA flow cytometry, New England Journal of Medicine 320 (1989), 627-633.

[8] G. Clark, M.-C. Mathieu, M. Owens, L. Dressler, L. Eudey, D. Tormey et al., Journal of Clinical Oncology 10 (1992), 428-432.

[9] C. Cornelisse, C. van de Velde, R. Caspers, A. Moolenaar and J. Hermans, DNA ploidy and survival in breast cancer patients, Cytometry 8 (1987), 225-234. 
[10] D.D. Davey, E.R. Banks, D. Jennings and D.E. Powell, Comparison of nuclear grade and DNA cytometry in breast carcinoma aspirates to histologic grade in excised cancers, American Journal of Clinical Pathology 99(6) (1993), $708-713$.

[11] A. Deitch, Cytophotometry of nucleic acids, in: Introduction to Quantitative Cytochemistry, G.L. Weid, ed., Academic Press, London, 1966, pp. 327-354.

[12] M.J. Eskelinen, P. Parjarnen, Y. Collan, E. Pesonen, E. Alhava, K. Kettunen and S. Nordling, Relationship between DNA ploidy and survival in patients with primary breast cancer, British Journal of Surgery 76 (1989), 830-834.

[13] S. Ewers, R. Attewell, B. Baldetorp, A. Borg and K.D. Langstrom, Prognostic potential of flow cytometric S-phase and ploidy prospectively determined in primary breast carcinomas, Breast Cancer Research and Treatment 20 (1991), 93-108.

[14] B. Fisher, N. Gunduz, J. Costantino, E. Fisher, C. Redmond, Marmounas et al., DNA flow cytometric analysis of primary operable breast cancer: relation of ploidy and S-phase fraction to outcome of patients in NSABP, Cancer 68 (1991), 1465-1475.

[15] Y.S. Fu and T.L. Hall, DNA ploidy measurements in tissue sections, Analytical Quantitative Cytology and Histology 7 (1985), 90-96.

[16] V.S. Ghali, S. Liau, C. Teplitz and R. Prudente, A comparative study of DNA ploidy in 115 fresh-frozen breast carcinomas by image analysis versus flow cytometry, Cancer 70(11) (1992), 2668-2672.

[17] C.M. Hunt, I.O. Ellis, C.W. Elston, A. Locker, D. Pearson and R.W. Blamey, Cytological grading of breast carcinoma - a feasible proposition?, Cytopathology 1 (1990), 287-295.

[18] O.P. Kallioniemi, G. Blanco, M. Alavaikko et al., Tumour DNA ploidy as an independent prognostic factor in breast cancer, British Journal of Cancer 56 (1987), 637-642.

[19] O. Kallioniemi, G. Blanco, M. Alavaikko, T. Hietanen, J. Mattila, K. Lauslahti et al., Improving the prognostic value of DNA flow cytometry in breast cancer by combining DNA index and S-phase fraction, Cancer 62 (1988), 2183-2190.

[20] P.J. Klemi and H. Joensuu, Comparison of DNA ploidy in routine fine needle aspiration biopsy samples and paraffinembedded tissue samples, Analytical Quantitative Cytology and Histology 10(3) (1988), 195-199.

[21] B.H. Mayall, Current capabilities and clinical applications of image cytometry, Cytometry 3 (Suppl.) (1988), 78-84.

[22] J. Mossler, K. McCarthy, B. Woodward, L. Mitchner and E. Johnston, Correlation of mean nuclear area with estrogen receptor content in aspiration cytology of breast carcinoma, Acta Cytologica 26 (1982), 417-421.

[23] J. Mouriquand, M. Gozlan-Fior, Villemain et al., Value of cytoprognostic classification in breast carcinomas, Journal of Clinical Pathology 39 (1986), 489-496.

[24] S. O'Reilley, R. Camplejohn, D. Barnes, R. Millis, R. Rubens and M. Richards, Node-negative breast cancer: prognostic subgroups defined by tumour size and flow cytometry, Journal of Clinical Oncology 8 (1990), 2040-2046.

[25] T. Powles, A randomised trial of adjuvant versus neoadjuvant endocrine chemotherapy of operable breast cancer, Breast 2 (1993), 199-205.

[26] I.A. Robinson, G. McKee, A. Nicholson, J. D'Arcy, P.A. Jackson, M.G. Cook and M.W. Kissin, Prognostic value of cytological grading of fine-needle aspirates from breast carcinomas, Lancet 343 (1994), 947-949.

[27] Royal College of Pathologists Working Group, Pathology reporting in breast cancer screening, Journal of Clinical Pathology 44 (1991), 710-725.

[28] W. Sandritter, M. Carl and W. Ritter, Cytomorphometric measurements of the DNA content of human malignant tumors by means of the Feulgen reaction, Acta Cytologica (Baltimore) 10 (1966), 26-30.

[29] S.K. Sarker, R. Mendiola, A.D. Spigelman, M. Walker and D.V. Coleman, DNA ploidy on cytologic and tissue sections of breast lumps: a comparison using image analysis, Analytical Quantitative Cytology and Histology 18(1) (1996), 19-22.

[30] H. Schimmelpenning, E.T. Eriksson, B. Franzen, A. Zetterberg and G.U. Auer, Prognostic value of the combined assessment of proliferating cell nuclear antigen immunostaining and nuclear DNA content in invasive human mammary carcinomas, Vichows Archiv - Pathological Anatomy and Histopathology 423(4) (1993), 273-279.

[31] E. Schulte and C. Wittekind, The influence of wet fixed Papanicolaou and the air dried Giemsa technique on nuclear parameters in breast cancer cytology: a cytomorphometric analysis, Diagnostic Cytopathology 3 (1987), 256-261.

[32] R. Silvestrini, M. Daidone and G. Gasparini, Cell kinetics as a prognostic marker in node-negative breast cancer, Cancer 56 (1985), 1982-1987.

[33] H. Sigurdsson, B. Baldetorp, A. Borg, M. Dalberf, M. Ferno, D. Kilander et al., Indicators of prognosis in nodenegative breast cancer, New England Journal of Medicine 322 (1990), 1045-1053.

[34] I. Smith, A. Jones, M. O’Brien, J. McKinner and M. Baum, Primary medical (neo-adjuvant) chemotherapy for operable breast cancer, European Journal of Cancer 29 (1993), 1796-1799.

[35] J. Thomas, E. Mallon and W. George, Semiquantitative analysis of fine needle aspirates from benign and malignant breast lesions, Journal of Clinical Pathology 42 (1989), 28-34.

[36] D. Winchester, R. Duda, C. August, R. Goldschmidt, D. Wruck, A. Rademaker et al., The importance of DNA flow cytometry in node-negative breast cancer, Archives of Surgery 125 (1990), 886-889. 
[37] A. Zajdela, L. DeLaRiva and N. Ghossein, The relation of prognosis to the nuclear diameter of breast cancer cells obtained by cytologic aspiration, Acta Cytologica 23 (1984), 75-80.

[38] S. Zurrida, M. Greco and U. Veronesi, Surgical aspects of the conservative treatment of large size breast cancers after primary chemotherapy, Breast 2 (1993), 187-192. 


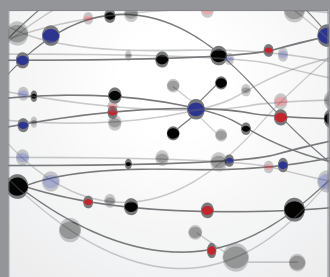

The Scientific World Journal
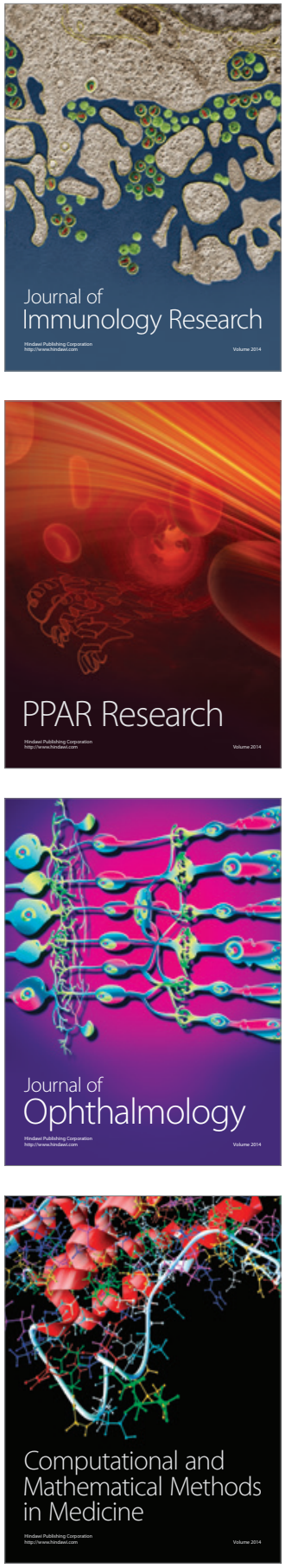

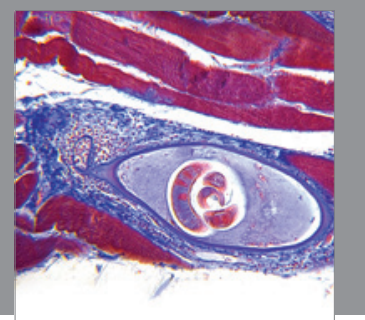

Gastroenterology

Research and Practice
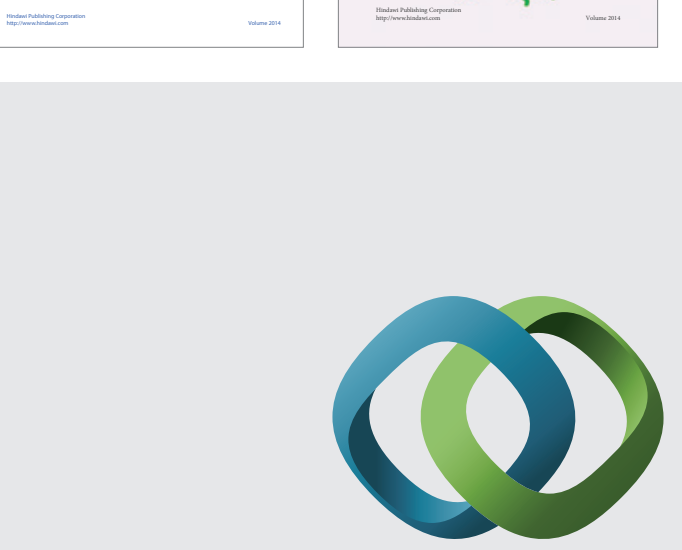

\section{Hindawi}

Submit your manuscripts at

http://www.hindawi.com
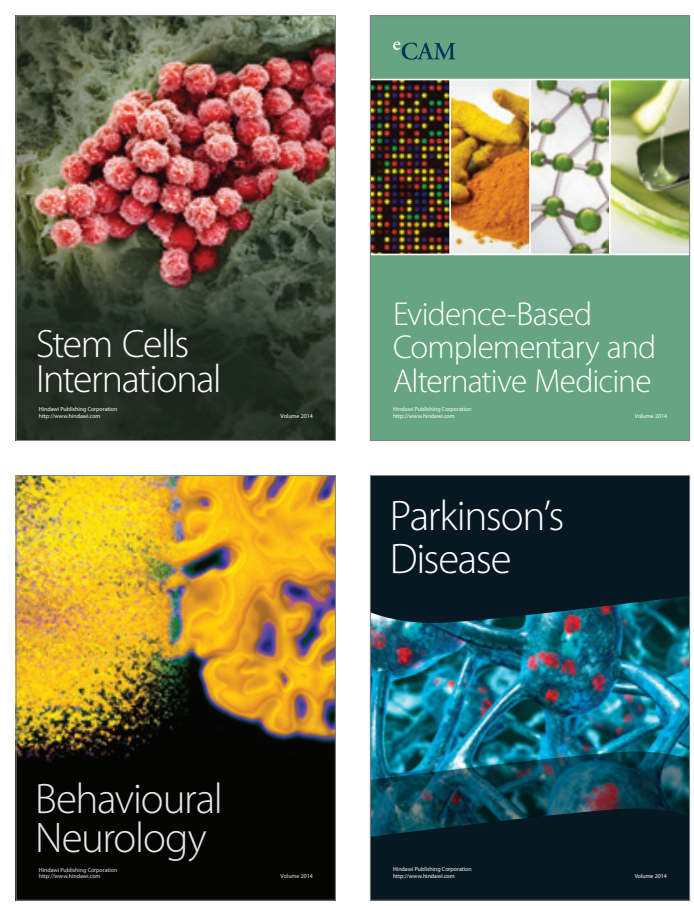

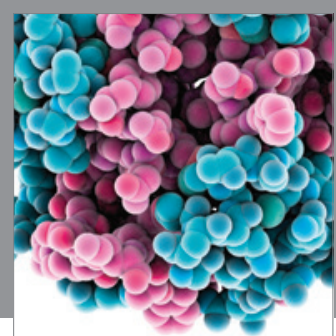

Journal of
Diabetes Research

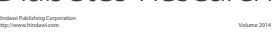

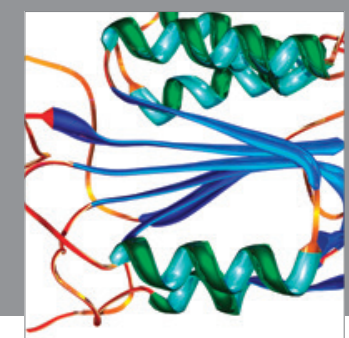

Disease Markers
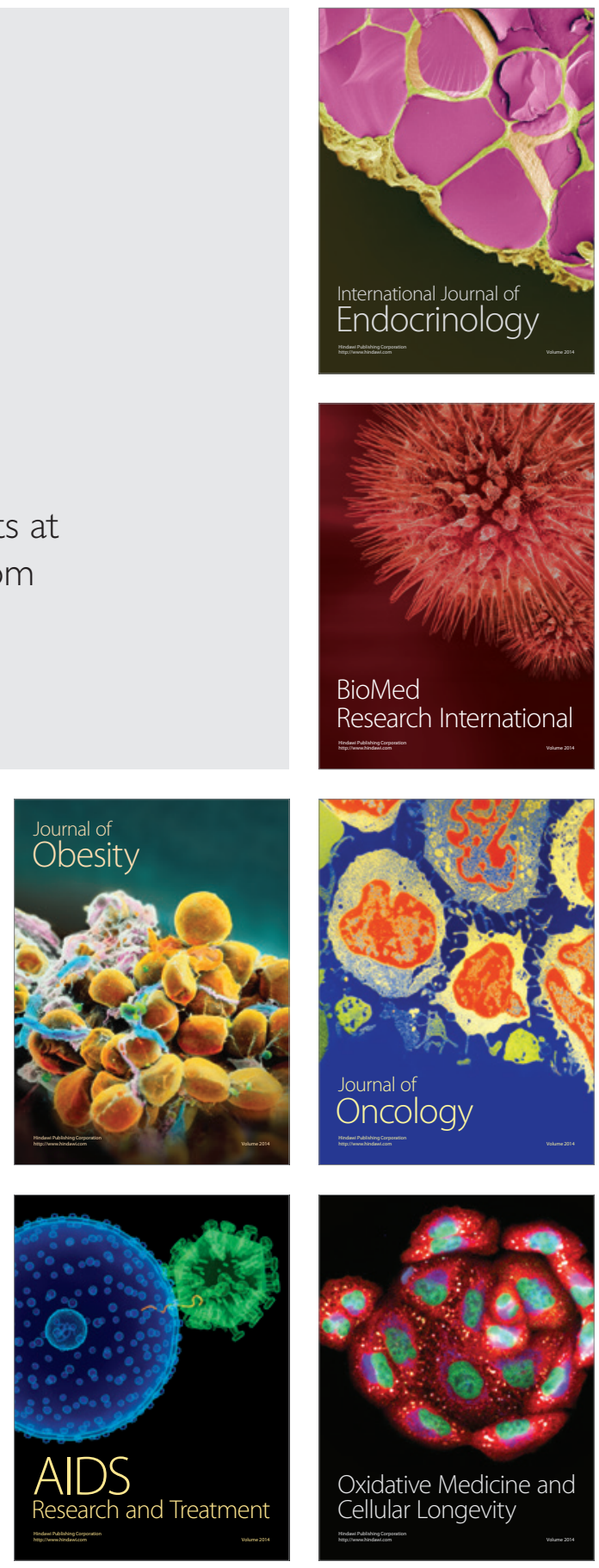